\title{
Short-Term Changes in Intraocular Pressure After Intravitreal Injection of Bevacizumab for the Treatment of Retinopathy of Prematurity
}

This article was published in the following Dove Press journal: Clinical Ophthalmology

\author{
Shumpei Obata $\mathbb{1}^{1}$ \\ Tomoaki Higashiyama' \\ Taku Imamura' \\ Masashi Kakinoki' \\ Takahide Yanagi $\mathbb{( D}^{2}$ \\ Yoshihiro Maruo ${ }^{2}$ \\ Masahito Ohji' \\ 'Department of Ophthalmology, Shiga \\ University of Medical Science, Otsu, \\ Japan; ${ }^{2}$ Department of Pediatrics, Shiga \\ University of Medical Science, Otsu, Japan
}

Correspondence: Shumpei Obata Department of Ophthalmology, Shiga University of Medical Science, Seta Tsukinowacho, Otsu, Shiga 520-2192, Japan

Tel +8I-77-548-2276

Fax +8I-77-548-2279

Email obata326@belle.shiga-med.ac.jp
Purpose: To evaluate short-term changes in intraocular pressure after intravitreal injection of bevacizumab for retinopathy of prematurity.

Patients and methods: This study was a prospective case-series. Consecutive infants underwent intravitreal injection with bevacizumab for type 1 retinopathy of prematurity at a university hospital. Intraocular pressure was measured with tonometer at baseline, at $1 \mathrm{~min}$, and at 3,10, 30 and 60 mins after injection.

Results: Five patients (four boys) were enrolled in this study. Mean ( \pm standard deviation) intraocular pressure was $8.0 \pm 2.4 \mathrm{mmHg}$ (range: $6-11.5 \mathrm{mmHg}$ ) just before the intravitreal injection, and the pressures were $19.8 \pm 2.8 \mathrm{mmHg}(16.4-23.9 \mathrm{mmHg}), 14.6 \pm 4.4 \mathrm{mmHg}$ (7.6-18.4 mmHg), $11.2 \pm 4.2 \mathrm{mmHg}(6.4-16.5 \mathrm{mmHg}), 9.3 \pm 3.5 \mathrm{mmHg}(5.8-13.2 \mathrm{mmHg})$, and $8.2 \pm 1.4 \mathrm{mmHg}(6.9-10.0 \mathrm{mmHg})$ at $1 \mathrm{~min}, 3,10,30$ and $60 \mathrm{mins}$ after the injection, respectively. Mean intraocular pressure after $1 \mathrm{~min}$ was significantly higher than intraocular pressure before injection $(\mathrm{p}=0.02)$. Pressures decreased between $1 \mathrm{~min}$ and 3 mins after intravitreal injection, although there was no statistically significant difference between the pressures at those time-points. Intraocular pressures after 3, 10, 30 and 60 mins were not significantly different from the pressure before injection.

Conclusion: Intraocular pressure elevation after intravitreal injection of bevacizumab for neonatal infants may be mild, so there may be a limited risk due to intraocular pressure after intraocular injection of bevacizumab for retinopathy of prematurity.

Keywords: retinopathy of prematurity, intraocular pressure, bevacizumab

\section{Introduction}

Retinopathy of prematurity (ROP) remains a leading cause of childhood blindness worldwide. ${ }^{1}$ Early use of conventional laser therapy, which has been recommended to treat stage $3+\mathrm{ROP}$, results in better outcomes than does late laser treatment. ${ }^{2}$ Although the overall anatomical and visual outcomes of ROP have improved because of proper screening and laser treatment, the outcome of treatment for Zone-I ROP is still unsatisfactory. $^{3-5}$ The "Bevacizumab Eliminates the Angiogenic Threat of Retinopathy of Prematurity" (BEAT-ROP) study showed improved outcomes with intravitreal injection of bevacizumab (IVB) compared with conventional laser photocoagulation for Zone-I ROP. ${ }^{6}$ IVB is now commonly performed worldwide for ROP. IVB is also performed in adult patients with diabetic retinopathy, age-related macular degeneration, retinal vein occlusion. In previous reports on intraocular pressure (IOP) changes in adults, IVB resulted in a transient but significant increase in IOP, to 
35-55 mmHg, immediately or within $1 \mathrm{~min}$ after the injection, thereby negatively affecting the retinal and optic nerve blood supply. ${ }^{7-11}$ There is only one report about IOP changes after IVB for ROP. In that study, IVB resulted in a transient but significant increase in IOP, to $40.1 \mathrm{mmHg}$, immediately after the injection. ${ }^{12}$ The possible changes in IOP after IVB for ROP are still not fully known. Because the amount injected into the vitreous cavity differs between adults and neonatal infants, and, because the rigidity of the eyeball may differ between age groups, IOP changes after IVB for ROP might differ from IOP changes after injections in adults. In this study, we investigated such IOP changes in infants.

\section{Subjects and Methods}

This prospective study was registered at http://www.umin. ac.jp (No. UMIN000029512). This study protocol was approved by the Institutional Review Board/Ethics Committee of Shiga University of Medical Science Hospital and adhered to the tenets of the Declaration of Helsinki. This was a prospective case-series study of consecutive patients undergoing IVB for ROP from April to December 2018 at the university hospital. The parents of all participants signed informed consent forms before IVB treatment. Off-label use of bevacizumab was approved by the Institutional Review Board/Ethics Committee of Shiga University of Medical Science Hospital.

Patients with type 1 ROP (as defined by the Early Treatment for Retinopathy of Prematurity study) ${ }^{2}$ who received IVB were enrolled. Intravitreal injections were performed by two ophthalmologists. Topical 4\% lidocaine hydrochloride and $1.25 \%$ povidone iodine were instilled in the eyes before intravitreal injection. Intravitreal injection of $0.625 \mathrm{mg}$ $(0.025 \mathrm{~mL})$ bevacizumab was performed with a 29-gauge needle vertically through the pars plana $0.75-1.0 \mathrm{~mm}$ posterior to the limbus, with patients under general anesthesia induced by midazolam and fentanyl with tracheal cannulation. The needle was inserted approximately $3-5 \mathrm{~mm}$ into the eyeball before injection. IOP was measured just before IVB and at 1 min, 3, 10, 30 and 60 mins after injection, with an Icare ${ }^{\circledR}$ PRO rebound tonometer (Icare, Helsinki, Finland). All measurement was performed under general anesthesia. We chose the general anesthesia to reduce the risk of adverse events by patient's movement. Axial length, depth of the anterior chamber and depth of the lens were measured with an AL 4000 ultrasound biometer (Tomey, Nagoya, Japan) at baseline.

Statistical analyses were performed using GraphPad Prism 6 software (GraphPad Software, Inc., La Jolla, $\mathrm{CA})$. The results have been expressed as the mean \pm standard deviation (SD) for continuous variables. The baseline values and individual values of IOP at each timepoint were analyzed using paired t-tests. P-values less than 0.05 were considered significant.

\section{Results}

Five patients (four boys and one girl) with type 1 ROP were enrolled in this study. Gestational age at birth ranged from 25 weeks 1 day to 32 weeks (mean: 26 weeks 4 days). Birth weights ranged from 428 to $1348 \mathrm{~g}(813.8 \pm 333.7 \mathrm{~g})$. PMA at the time of IVB ranged from 33 weeks 6 days to 38 weeks 6 days (mean: 35 weeks 6 days). For the treated eyes at the time of IVB: axial length ranged from 18.5 to $19.5 \mathrm{~mm}$ (19 \pm $0.6 \mathrm{~mm}$ ), depth of the anterior chamber ranged from 1.7 to $2.6 \mathrm{~mm} 2.0 \pm 0.4 \mathrm{~mm}$ ) and the thickness of the crystalline lens ranged from 3.6 to $4.4 \mathrm{~mm}(4.0 \pm 0.3 \mathrm{~mm})$. Measurements for the individual participants are provided in Table 1.

As shown in Figure 1 and Table 2, mean IOP was $8.0 \pm$ $2.4 \mathrm{mmHg}(6-11.5 \mathrm{mmHg})$ before IVB. The mean values of IOP were $20 \pm 2.8 \mathrm{mmHg}(16.4-22.1 \mathrm{mmHg}), 14.6 \pm 4.4$ $\mathrm{mmHg}(16.4-22.1 \mathrm{mmHg}), 11.2 \pm 4.2 \mathrm{mmHg}(6.4-16.5$ $\mathrm{mmHg}), 9.3 \pm 3.5 \mathrm{mmHg}(5.8-13.2 \mathrm{mmHg})$, and $8.2 \pm 1.4$ $\mathrm{mmHg}(6.9-10.0 \mathrm{mmHg})$ at $1 \mathrm{~min}$ and 3, 10, 30 and $60 \mathrm{mins}$ after IVB, respectively. Mean IOP after 1 min was significantly increased relative to IOP before injection $(p=0.02)$.

Table I Baseline Characteristics of Patients

\begin{tabular}{|l|l|l|l|l|l|l|}
\hline $\begin{array}{l}\text { Patient No./ Sex/ } \\
\text { PMA(Weeks) }\end{array}$ & $\begin{array}{l}\text { Weight at } \\
\text { Birth } \mathbf{( g )}\end{array}$ & $\begin{array}{l}\text { Study } \\
\text { Eye }\end{array}$ & $\begin{array}{l}\text { Day of } \\
\text { Injection }\end{array}$ & $\begin{array}{l}\text { Axial Length } \\
(\mathbf{m m})\end{array}$ & $\begin{array}{l}\text { Depth of Anterior } \\
\text { Chamber }(\mathbf{m m})\end{array}$ & $\begin{array}{l}\text { Thickness of } \\
\text { Lens }(\mathbf{m m})\end{array}$ \\
\hline I/F/25wld d & 428 & L & $36 w 2 d$ & 18.64 & 1.65 & 3.6 \\
2/M/32w & 1348 & L & $38 w 6 d$ & 18.05 & 2.57 & 3.97 \\
3/M/26w & 802 & L & $33 w 6 d$ & 19.01 & 1.79 & 3.99 \\
4/M/25wId & 774 & L & $34 w 2 d$ & 19.25 & 1.82 & 4.12 \\
5/M/25wId & 717 & L & $36 w$ & 19.71 & 1.91 & 4.37 \\
\hline
\end{tabular}

Note: ${ }^{a} 25$ wld (ie, 25 weeks plus I day).

Abbreviation: PMA, postmenstrual age. 


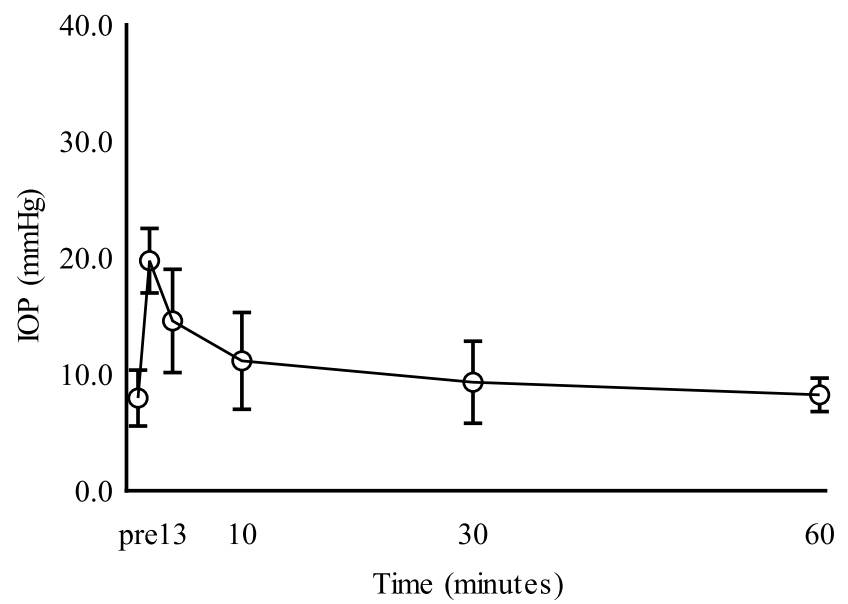

Figure I Changes in intraocular pressure (IOP) after intravitreal injection of bevacizumab. Only the IOP at I min after injection was significantly different from that at baseline "pre".

IOP decreased between $1 \mathrm{~min}$ and 3 mins after IVB, although there was no statistically significant difference between the values at those two times. IOPs at 3, 10, 30 and 60 mins after injection were not significantly higher than the IOP before injection. The highest IOP measured in this study was $23.9 \mathrm{mmHg}$ at $1 \mathrm{~min}$ after IVB; that patient's IOP had decreased to $18.4 \mathrm{mmHg}$ at $3 \mathrm{mins}$ after IVB.

\section{Discussion}

In adults, several reports have demonstrated acute IOP elevation after intravitreal injection, due to the acute increase in volume inside the eye..$^{7-11}$ The amount of bevacizumab used in ROP was $0.625 \mathrm{mg}(0.025 \mathrm{~mL})$, which is half of the amount for adults, whereas the ocular volume of neonatal infants at 37 weeks is almost one-third of that of adults, based on the axial lengths in a previous report. ${ }^{13}$ As is the case in adults, substantial IOP elevation was a concern regarding IVB for ROP. In adults, IOP has been reported to increase to $35-55 \mathrm{mmHg}$ immediately after the injection or within 1 min..$^{7-11}$ In our study, mean IOP was $8.0 \mathrm{mmHg}$ $(6-11.5 \mathrm{mmHg})$ before the injection. At $1 \mathrm{~min}$ after the injection, IOP was significantly increased to $19.8 \mathrm{mmHg}$
(16.4-23.9 mmHg). The post-injection IOP values remained at less than $30 \mathrm{mmHg}$ in all of the eyes, with the highest IOP measured in this study being $23.9 \mathrm{mmHg}$ at $1 \mathrm{~min}$ after IVB in patient No. 1. Therefore, IOP elevation after IVB in neonatal infants seems to be milder than that in adults.

The reason why IOP was elevated at $1 \mathrm{~min}$ is that bevacizumab was injected into the vitreous cavity which was closed space. As shown in Table 2, the IOP might be gradually decreased from $1 \mathrm{~min}$ and the IOP at 3 mins was under $20 \mathrm{mmHg}$ in all patients because the aqueous humor was absorbed through trabeculum. In addition, in this study, obvious reflux after IVB was not detected; however, very slow reflux which was not detected as a conjunctival bleb might be occurred. This reflux might also relate to the IOP decreasing.

There are several possible explanations for differences in IOP elevation after IVB between neonatal infants and adults. First, the amount injected into the vitreous cavity differs between adults and neonates. The volume of bevacizumab injected in adults is $0.05 \mathrm{~mL}$, whereas the volume of bevacizumab was $0.025 \mathrm{~mL}$ for ROP in this study. The mean axial length was $23.2 \pm 1.1 \mathrm{~mm}$ for adults in a previous report. ${ }^{14}$ In our study, the mean axial length was $18.9 \pm 0.6 \mathrm{~mm}$ for neonatal infants. As would be expected, the ocular volume of these neonatal infants was smaller than that of adults, but the ocular volume of the infants was already almost half of that of adults, based on the axial lengths in the current report. The volume in each injection, as compared to the volume of vitreous, might cause the difference in results between adults and neonatal infants. Second, IOP of the infants at baseline was lower than that of adults. The mean IOP at baseline was $16.7 \pm 3.5 \mathrm{mmHg}$ for adults in the previous report. ${ }^{14}$ In our study, the IOP at baseline was $8.0 \pm 2.4 \mathrm{mmHg}$ for the infants. The difference in IOP at baseline might account for the different IOP changes between adults and neonatal infants. Intravitreal injections in adults are performed with only topical anesthesia, but IVB in the

Table 2 Intraocular Pressure $(\mathrm{mmHg})$

\begin{tabular}{|l|l|l|l|l|l|l|}
\hline Patient No & Before IVB & I min After IVB & 3 mins After IVB & I0 mins After IVB & 30 mins After IVB & 60 mins After IVB \\
\hline I & 6.3 & 23.9 & 18.4 & 16.5 & 12.8 & 9.6 \\
2 & 9.4 & 20.3 & 12.8 & 6.4 & 5.8 & 10.0 \\
3 & 11.5 & 16.4 & 7.6 & 7.6 & 6.2 & 6.9 \\
4 & 6.0 & 19.9 & 17.4 & 13.3 & 8.6 & 7.3 \\
5 & 6.6 & 18.3 & 16.7 & 12.0 & 13.2 & 7.4 \\
\hline
\end{tabular}

Abbreviation: IVB, Intravitreal injection of bevacizumab. 
neonatal infants in this study was performed under general anesthesia. IOP decreased during general anesthesia in a previous report; IOP was $15.3 \mathrm{mmHg}$ before induction of general anesthesia, but at the end of surgery, IOP was $11.2 \mathrm{mmHg}(\mathrm{p}<0.01) .{ }^{15}$ In another explanation, the drainage system of aqueous humor in the elderly may already be compromised and hence a big IOP spike compared to children. Therefore, there could be multiple factors contributing to the relatively small increase in IOP elevation after IVB for neonatal infants, as compared to the elevation for adults.

To our knowledge, there is only one earlier report about changes in IOP after IVB for ROP. IVB resulted in a transient but significant increase in IOP, to $40.1 \mathrm{mmHg}$ from $12.3 \mathrm{mmHg}$, immediately after the injection in that report. $^{12}$ In contrast, IOP elevation after IVB for neonatal infants was milder in our study than in the previous report. In both populations, there is a tripling of IOP from baseline. There are several possible explanations for differences in IOP elevation after IVB between this report and the previous report. The timing of the first IOP measurement after IVB was different between this report with measurements at $1 \mathrm{~min}$ after IVB and the previous one with measurement immediately after IVB, and, respectively, in the two studies. IOP $(8.0 \pm 2.4 \mathrm{mmHg})$ at baseline in this report was lower than it $(12.3 \pm 3.0 \mathrm{mmHg})$ in the previous report by Kato et al. All IOP measurements were performed under general anesthesia which was used the same medicine between this report and the previous report. Because the detail about anesthesia was not explained in the previous report, the dose might be different. In this report, we did not ophthalmic examination by ocular compression and/or RetCam (Clarity Medical, Pleasanton, CA). Such an examination might induce the IOP decreasing by ocular compression. Therefore, the difference of IOP at baseline was not be able to explain clearly. However, differences in IOP before IVB might also differentially impact the rate of IOP elevation in this study and the previous study. ${ }^{12}$ In both studies, Icare PRO was used to measure IOP. In the previous report, a 30-gauge needle was used, but in this report, a 29-gauge needle was used.

In this report, IOP elevation after IVB for neonatal infants was smaller in our study than in the previous report. The injected volume in this study was $0.025 \mathrm{~mL} / 0.625 \mathrm{mg}$ which was the same as in the BEAT-ROP study; ${ }^{6}$ however, the other report showed a dose of bevacizumab as low as $0.031 \mathrm{mg}$, or $5 \%$ of the dose used in the BEAT-ROP study, ${ }^{6}$ was effective in 9 of 9 eyes. ${ }^{19}$ In the future study, reduced dose might be recommended to treat the ROP.

A limitation of the current study was the small sample size. We cannot say that IVB for neonates would always be safe, so safety should be confirmed in a study with a larger sample size. The use of general anesthesia in this study also limits its widespread applicability. However, our results are useful because IVB is performed under general anesthesia at least in some institutes. ${ }^{16-18}$

\section{Conclusion}

In conclusion, IOP was elevated at $1 \mathrm{~min}$ after the injection in all five infants. However, IOP elevation after IVB for neonatal infants may be mild, so the risk due to IOP after IVB for ROP might be limited.

\section{Acknowledgment}

We thank Claire Barnes, $\mathrm{PhD}$, from Edanz Group for editing a draft of this manuscript.

\section{Disclosure}

TH reports personal fees from Senju Pharmaceutical and Pfizer Japan; grants from JSPS KAKENHI and Novartis Pharmaceutical Company, outside the submitted work. YM reports personal fees from Maruho Co., JCR Pharmaceutical, Toyama Chemical Co., Sandoz, Kyowa Kirin Co., Otsuka Pharmaceutical, Ohtsuka Chemical Industrial, Pfizer, Actelion, Pharmaceuticals Japan, NovoNordisk, Sanofi and Alexion, outside the submitted work. MO reports grants and personal fees from Novartis, Santen Pharmaceutical, Alcon JAPAN, Otsuka Pharmaceutical, Senjyu Pharmaceutical, Pfizer and Bayer Yakuhin, grants from HOYA Corporation, personal fees from Allergan and Kowa Pharmaceutical company, outside the submitted work. The authors report no other conflicts of interest in this work.

\section{References}

1. Gilbert C. Retinopathy of prematurity: a global perspective of the epidemics, population of babies at risk and implications for control. Early Hum Dev. 2008;84(2):77-82. doi:10.1016/j.earlhumdev.2007. 11.009

2. Early Treatment For Retinopathy Of Prematurity Cooperative G. Revised indications for the treatment of retinopathy of prematurity: results of the early treatment for retinopathy of prematurity randomized trial. Arch Ophthalmol. 2003;121(12):1684-1694. doi:10.1001/ archopht.121.12.1684

3. Kychenthal A, Dorta P, Katz X. Zone I retinopathy of prematurity: clinical characteristics and treatment outcomes. Retina. 2006;26(7 Suppl):S11-5. doi:10.1097/01.iae.0000244285.79004.e6 
4. Soh Y, Fujino T, Hatsukawa Y. Progression and timing of treatment of zone I retinopathy of prematurity. Am J Ophthalmol. 2008;146 (3):369-374. doi:10.1016/j.ajo.2008.05.010

5. Drenser KA, Trese MT, Capone A Jr. Aggressive posterior retinopathy of prematurity. Retina. 2010;30(4 Suppl):S37-S40. doi:10.10 97/IAE.0b013e3181cb6151

6. Mintz-Hittner HA, Kennedy KA, Chuang AZ, Group B-RC. Efficacy of intravitreal bevacizumab for stage 3+ retinopathy of prematurity. N Engl J Med. 2011;364(7):603-615. doi:10.1056/NEJMoa1007374

7. Benz MS, Albini TA, Holz ER, et al. Short-term course of intraocular pressure after intravitreal injection of triamcinolone acetonide. Ophthalmology. 2006;113(7):1174-1178. doi:10.1016/j.ophtha.2005.10.061

8. Falkenstein IA, Cheng L, Freeman WR. Changes of intraocular pressure after intravitreal injection of bevacizumab (avastin) Retina. 2007;27(8):1044-1047. doi:10.1097/IAE.0b013e3180592ba6

9. Hollands H, Wong J, Bruen R, Campbell RJ, Sharma S, Gale J. Short-term intraocular pressure changes after intravitreal injection of bevacizumab. Can J Ophthalmol. 2007;42(6):807-811. doi:10.3129/i07-172

10. Kim JE, Mantravadi AV, Hur EY, Covert DJ. Short-term intraocular pressure changes immediately after intravitreal injections of anti-vascular endothelial growth factor agents. Am J Ophthalmol. 2008;146(6):930-4 e1. doi:10.1016/j.ajo.2008.07.007

11. Lee JW, Park H, Choi JH, et al. Short-term changes of intraocular pressure and ocular perfusion pressure after intravitreal injection of bevacizumab or ranibizumab. BMC Ophthalmol. 2016;16:69. doi:10.1186/s12886-016-0255-8

12. Kato A, Okamoto Y, Okamoto F, Saito M, Miyazono Y, Oshika T. Short-term intraocular pressure changes after intravitreal injection of bevacizumab for retinopathy of prematurity. Jpn J Ophthalmol. 2019;63(3):262-268. doi:10.1007/s10384-019-00661-y
13. Tucker SM, Enzenauer RW, Levin AV, Morin JD, Hellmann J. Corneal diameter, axial length, and intraocular pressure in premature infants. Ophthalmology. 1992;99(8):1296-1300. doi:10.1016/S01616420(92)31812-3

14. Cacciamani A, Oddone F, Parravano M, Scarinci F, Di Nicola M, Lofoco G. Intravitreal injection of bevacizumab: changes in intraocular pressure related to ocular axial length. Jpn J Ophthalmol. 2013;57(1):63-67. doi:10.1007/s10384-012-0194-8

15. Muint Y, Singh AK, Peacock JE, Padfield A. Changes in intra-ocular pressure during general anaesthesia: a comparison of spontaneous breathing through a laryngeal mask with positive pressure ventilation through a tracheal tube. Anaesthesia. 1995;50(2):126-129. doi:10.1111/j.1365-2044.1995.tb15094.x

16. Sato T, Wada K, Arahori H, et al. Serum concentrations of bevacizumab (avastin) and vascular endothelial growth factor in infants with retinopathy of prematurity. Am J Ophthalmol. 2012;153 (2):327-333 e1. doi:10.1016/j.ajo.2011.07.005

17. Hong YR, Kim YH, Kim SY, Nam GY, Cheon HJ, Lee SJ. Plasma concentrations of vascular endothelial growth factor in retinopathy of prematurity after intravitreal bevacizumab injection. Retina. 2015;35 (9):1772-1777. doi:10.1097/IAE.0000000000000535

18. Zhou Y, Jiang Y, Bai Y, Wen J, Chen L. Vascular endothelial growth factor plasma levels before and after treatment of retinopathy of prematurity with ranibizumab. Graefes Arch Clin Exp Ophthalmol. 2016;254(1):31-36. doi:10.1007/s00417-015-2996-0

19. Wallace DK, Kraker RT, Freedman SF, et al. Assessment of lower doses of intravitreous bevacizumab for retinopathy of prematurity: a phase 1 dosing study. JAMA Ophthalmol. 2017;135(6):654-656. doi:10.1001/jamaophthalmol.2017.1055
Clinical Ophthalmology

\section{Publish your work in this journal}

Clinical Ophthalmology is an international, peer-reviewed journal covering all subspecialties within ophthalmology. Key topics include: Optometry; Visual science; Pharmacology and drug therapy in eye diseases; Basic Sciences; Primary and Secondary eye care; Patient Safety and Quality of Care Improvements. This journal is indexed on PubMed
Dovepress

Central and CAS, and is the official journal of The Society of Clinical Ophthalmology (SCO). The manuscript management system is completely online and includes a very quick and fair peer-review system, which is all easy to use. Visit http://www.dovepress.com/ testimonials.php to read real quotes from published authors. 